\title{
Charcot foot (neuropathic arthropathy) in diabetes as a "special needs foot". Case report of an efficient negative pressure wound therapy use.
}

\author{
Bartosz Cybułka
}

\section{CASE REPORT}

\begin{abstract}
Diabetes is the most common endocrine disorder of carbohydrate metabolism. If left untreated, or improperly treated, diabetes leads to multiple organ complications. One of the serious consequences of the disease is damage to the peripheral and autonomic nerves known as diabetic neuropathy. The most advanced form of neuropathy, leading to damage to the structures of the forefoot, midfoot and hindfoot, is the so-called Charcot foot, or neuropathic osteoarthropathy. Irreversible damage to the structures of the foot affects between $0,1 \%$ and $7.5 \%$ of patients with diabetes.

The optimal care for that form of foot damage is still a subject to debate. Available methods of caring for Charcot foot include invasive orthopedic treatment and conservative treatment. The use of negative pressure wound therapy may be an effective, as well as transitional, way of managing Charcot foot.
\end{abstract}

Keywords-Charcot neuro - osteoarthropathy, Charcot foot, diabetic foot, diabetic neuropathy, negative pressure wound therapy (NPWT)

\section{INTRODUCTION}

D IABETES mellitus is the most common endocrine disorder. Impaired metabolism of carbohydrates leads to numerous organ complications. Epidemiologically, in 2011 there were 285 million patients with diagnosed diabetes. This number constituted $6.6 \%$ of the population aged 20-79. It is estimated that about one-third of cases still remain undiagnosed. Among them, 2.5\% will develop one of the most dangerous complications of diabetic foot, which is the Charcot arthropathy $]^{1}$

Osteoarticular lesions that result from disturbances of innervation, referred to as neuropathic arthropathy, were described in 1868 by Jean-Martin Charcot. ${ }^{2}$

Complicated form of diabetes is the most common cause of neuropathic arthropathy in developed countries. Any peripheral neuropathy may lead to articular lesions. Other causes that may, consequently, lead to lesions in the joint structure are: syringomyelia, poliomyelitis, injuries of the spinal cord, leprosy, alcohol abuse, multiple sclerosis, heavy metal poisoning and rheumatoid arthritis 3 ,

Manuscript received 17.07.2017; revised 28.03.2018. This work did not receive any financial support. Author declares no conflict of interest.

Author affiliations: Oddział Chirurgiczny z Pododdziałem Gastroenterologicznym Samodzielny Publiczny Zakład Opieki Zdrowotnej 62-065 Grodzisk Wlkp. ul. Mossego 3. , (BC)

*Correspondence to: Bartosz Cybułka: b.cybulka@wp.pl
The clinical classification of Charcot foot distinguishes the acute form of the disease, characterized by edema, redness, increased blood circulation, and increased foot temperature. Charcot arthropathy should be suspected in patients with these symptoms, without characteristic ulceration. The skin temperature of a diseased foot may be increased even by $2-6^{\circ} \mathrm{C}$. Pain intensity depends on the stage of diabetic neuropathy.

Charcot arthropathy is often diagnosed during the inactive, chronic stage when inflammatory symptoms are not present. In this phase, bones, joints and ligamentous apparatus of the foot are being continuously damaged. The use of imaging diagnostic (plain x-ray of the foot or magnetic resonance) confirms the clinical diagnosis. It is worth mentioning that the initial stage of metatarsal deformation will not be visible on a typical X-ray image in two projections. At the initial stage of the disease, magnetic resonance is the most sensitive imaging method.

In 1966, Sidney N. Eichenholtz described in his monograph cases of various osteoarticular lesions on the basis of 68 available radiograms, and introduced the term "Charcot joint" 6 (Tab. I)

\section{CASE REPORT}

A 58-year-old patient was admitted to a surgical ward for the treatment of a massive wound located between the second and third toe of the right foot. Medical history interview revealed a long-term insulin-dependent diabetes with numerous organ complications. Previously, the patient required amputation of the hallux of the right foot and the second toe of the left foot. Before the admission, the patient was provided with ambulatory care due to a non-healing clavus located on the plantar surface. Repeated resections of the clavus did not allow to eliminate this hyperkartotic lesion and during one of the visits, after a surgical resection of the clavus, an intervention to stop bleeding from blood vessels of the plantar surface was necessary.

Advanced destructive changes of the right foot were visible on an X-ray image (Fig. 1). The radiograms revealed the loss of the foot arch, fixed, spontaneous dislocation of the metatarsophalangeal joint, and foci of decreased mineralization in the tarsal and metatarsal bones (Fig. 2). No changes were observed at the level of the ankle joint and calcaneus. 
Table I

Classification of THE CHARCOT NEURO-ARTHROPATHY (EICHENHOlTZ 1966)

\begin{tabular}{lll}
\hline Stage & Clinical characteristics & X-ray features \\
\hline $\begin{array}{l}\text { Stage I (development or fragmen- } \\
\text { tation) }\end{array}$ & $\begin{array}{l}\text { Edema of diabetic foot. Inflammatory stage: - ode- } \\
\text { matous, - erythematous, - hot and hyperemic foot. }\end{array}$ & $\begin{array}{l}\text { Luxation, subluxation, dislocation of joint. Peri-articular frac- } \\
\text { tures. Foot deformity. Decrease of diabetic foot stability. } \\
\text { Stage II (coalescence) }\end{array}$ \\
$\begin{array}{l}\text { Gradual remission of the inflamatory skin signs. } \\
\text { Reduction of edema. } \\
\text { ftage III (consolidation or repara- } \\
\text { tion) }\end{array}$ & $\begin{array}{l}\text { Absence of inflamatory sility. } \\
\text { diabetic foot. }\end{array}$ & $\begin{array}{l}\text { Consolidated remodeling and deformation of the foot bones } \\
\text { and joints. }\end{array}$ \\
\hline
\end{tabular}

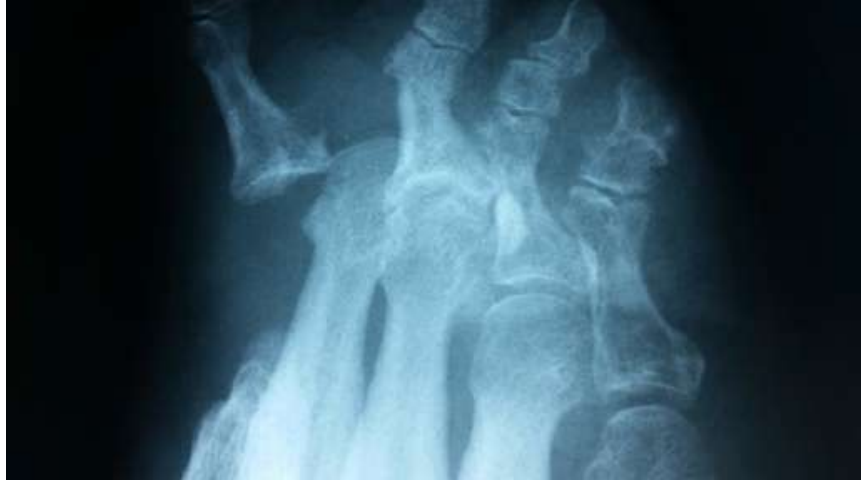

Figure 1. Displacement of the matatarsophalangeal joint (MTP). Sanders and Frykberg's classification - pattern I

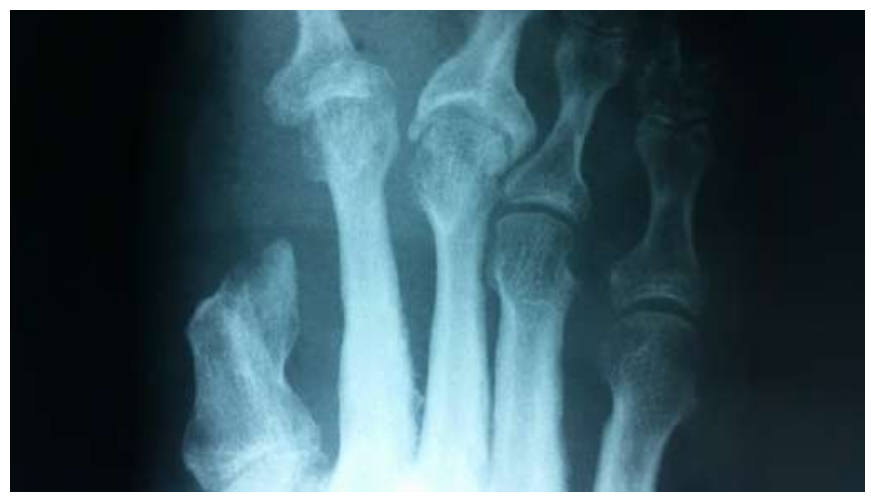

Figure 2. Previous amputation of the hallux

On the day of admission, after initial preparation of the bed and edge of the wound, a negative pressure dressing Vivano Tec produced by Hartmann was used. A $10 \mathrm{~cm}$ x $7.5 \mathrm{~cm} \mathrm{x}$ $3.3 \mathrm{~cm}$ sponge had been modeled to the elliptic shape of the wound. Due to the fact that the wound was located between toes, it required special attention to maintain the seal of the dressing (Fig. 3).

Continuous mode of negative pressure $(-125 \mathrm{mmHg})$ was applied. For better protection, the skin near the wound was covered with a stripe of silicon drape. The first dressing remained on the wound for 48 hours. During the first change of dressing, normal formation of granulation tissue and early signs of epithelialization of the wound edges were observed (Fig. 4). Negative pressure therapy was continued. The second negative pressure dressing remained intact for 72 hours. The third dressing set remained on the wound for 9

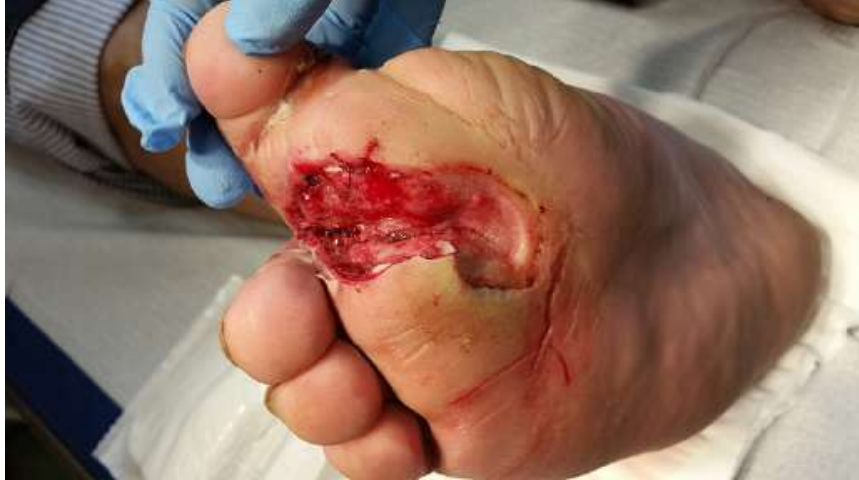

Figure 3. Management of the bleeding after initial debridement

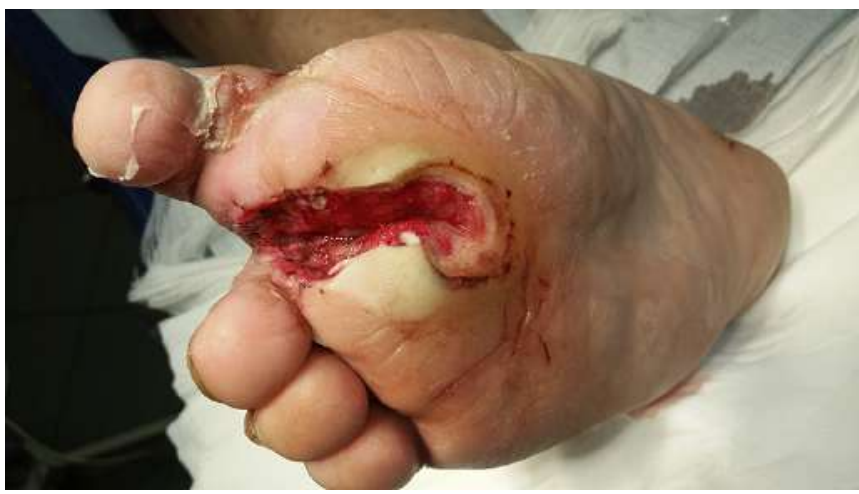

Figure 4. 1st wound dressing change after 48 hours of NPWT.

days due to full impermeability (Fig. 5). After the last 216hours course the negative pressure therapy was finished and a reduction of the total wound surface was observed, as well as a proliferation of the vital, healthy granulation tissue. The tendency of spontaneous wound edges approximation was also observed (Fig. 6).

Finally, the upper pole of the wound, between the second and third toe, was approximated with the use of an interrupted dermal suture (Dafilon 2.0). The defect, dressed in such a way, healed properly by further approximation of the wound edges (Fig. 7). No foci of necrosis, abnormal exudate, or clinical symptoms of infection were observed during the treatment of the wound. In this case, the course of healing of the wound in a deformed diabetic foot was finished successfully. 


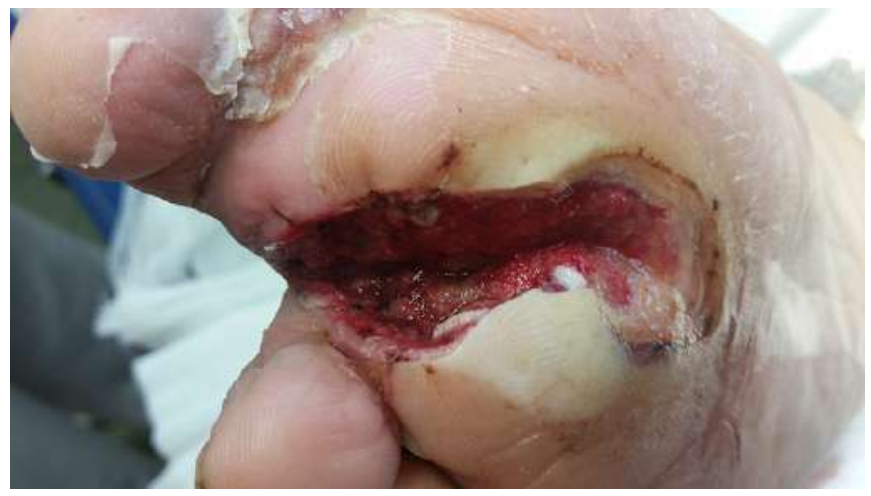

Figure 5. Granulation tissue and maceration of the epidermis

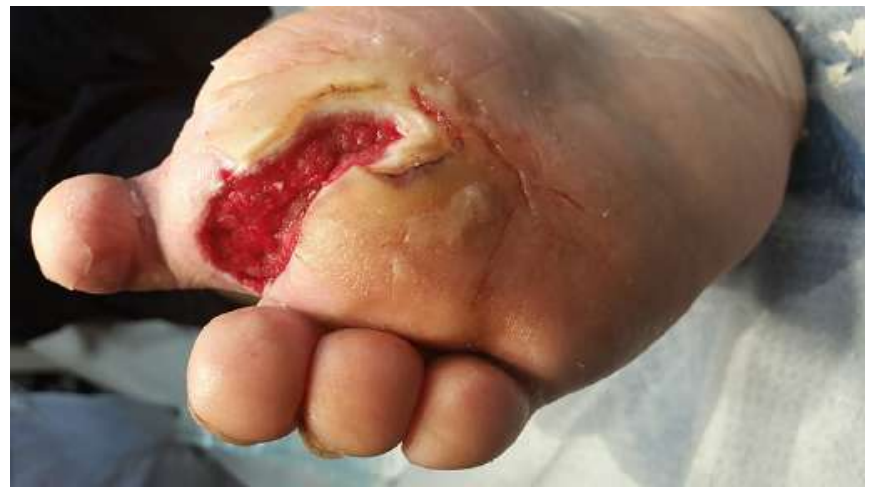

Figure 6. Evident reduction of tissue loss after 216 hours of continuous NPWT

\section{DISCUSSION}

Peripheral neuropathy relates to $29 \%$ of patients with diabetes mellitus.7 ${ }^{7}$ Charcot foot is a specific form of peripheral neuropathy in diabetes. Continuous destruction of nerve fibers leads to an autonomic neuropathy. Apart from hyposesthesia, blood circulation disorders and intensification of bone destruction are common this situation. The latter are due to the prevalence of osteolytic activity of osteoclasts on osteoblasts. The pathogenesis of Charcot foot is chronic, multifactorial, and progressive.

The chronic form of the disease is characterized by the reduction of edema, reduction of redness, reduction of

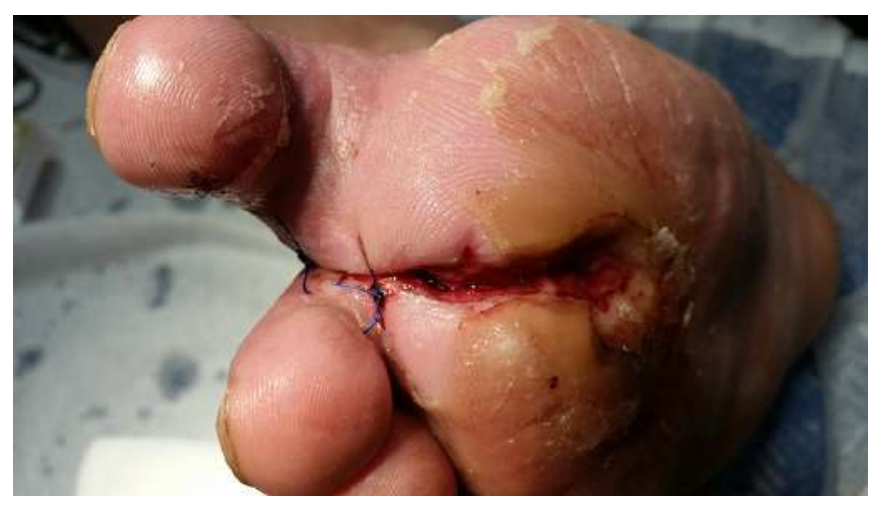

Figure 7. Postponed skin sutures in the diabetic foot increased temperature and leads to permanent anatomical changes at the level metatarsal level. A diabetic foot deformed in this process becomes more prone to repetitive minor unnoticed injuries that can further ulcerate. Disruption of the skin continuity opens the door for infection. Infectious complications in cases of diabetic foot are the most common cause of amputations in diabetes mellitus.

Neuropathy can relate to peripheral nerves that are responsible for transferring pain stimuli, as well as autonomic nerves determining the cellular equilibrium of the bones. In the advanced form of the diabetic foot, there is a prevalence of destructive activity of osteoclasts at the expense of osteogenic activity of the osteoblasts. Autonomic neuropathy leads to an increased arterial blood inflow by impairing arteriovenous capillary connections 89 Clinically, increased temperature, redness of foot skin and hypervolemia occur. ${ }^{[10}$ Increased blood flow also influences the bone tissue, leading to its increased resorption with bone mineral density loss 13

Peripheral neuropathy, referred to as the distal sensorimotor polyneuropathy is responsible for the loss of the protective pain, temperature, and touch sensation. A foot that is devoid of innervation is exposed to various kinds of damage that also disturb proper anatomy of the foot.

Another cause of foot damage is an increase of non-enzymatic glycation of collagen. Impaired collagen metabolism leads to the weakening of tendons, ligaments, therefore, leading to the change of foot biomechanics! 15

In the case of Charcot foot, there is an increased pressure impacting the plantar surface.

Characteristic clinical symptoms of Charcot neuroarthropathy are described using the 5D acronym according to Rajbhandari: 16

- joint distension

- dislocation

- debris

- disorganization

- increased density

If observed, any symptoms from foot fully oblige to prepare X-ray image of parts of the metatarsus. Visible changes characteristic for osteoarthropathy are dislocations and subluxations of foot joints, periarticular osteoporosis, bone tissue resorption, the presence of debris, loss of the foot arch, traces of previous surgical interventions.

Anatomical classification by Sanders and Frykberg differentiates five areas of foot damage. 17

I (15\%) lesions at the level of the forefoot, affecting the metatarsophalangeal (MTP) and interphalangeal (IP) joints.

II $(40 \%)$ affecting the tarsometatarsal joint (TMT). Lisfranc joint.

III (30\%) affecting the cuneonavicular, talonavicular, and calcaneocuboid joints. Chopart joint.

IV 10\%) affecting the ankle joint.

$\mathrm{V}(5 \%)$ affecting th ecalcaneus.

According to the American Orthopedic Foot and Ankle Society, an optimal manner of treating various lesions referred to as Charcot neuroarthropathy still evokes therapeutic 
controversies. It is one of the two most often discussed problems in this profession. 18

The most common cause of Charcot osteoarthropathy is diabetes mellitus. The most common location of lesions is the foot. Unfortunately, in most cases, accurate diagnosis is significantly delayed. In Pakarinen's observation, the time to accurate diagnosis was 29 weeks after emergence of first symptoms [19]. In another study, the delay in diagnosis was 10 weeks. 19

Appropriate treatment in advanced Charcot neuropathic osteoarthropathy is still a great therapeutic challenge. One of the available ways of Charcot foot treatment is an orthopedic operation. During an open surgery, any possible dislocation or subluxation of foot joints can be corrected. After repositioning of the joints, internal or external stabilization is used. Inserting an implant into foot bones is considered by many to be an unjustified practice.

In most cases, diabetic foot is treated conservatively. After initial termination of the inflammatory process, necrotic and ischaemic tissues are removed. Unfortunately, most cases of complicated diabetic foot require more radical procedures. In many patients, limbs need to be amputated below the level of talocrural joint. Such surgeries are referred to as minor amputations. Radical procedures at the level of the thigh or shin are called major amputations.

An optimal management in cases of Charcot neuropathic osteoarthropathy still evokes therapeutic controversies. Some patients require an orthopedic intervention with the use of bone connecting materials. A significant group of patients is treated conservatively due to an increased risk of infectious complications and coexistence of systemic complications of diabetes. Any form of diabetic foot is a real threat to lower limb amputation. A special case of diabetic neuropathy is Charcot arthropathy. Deformation of the anatomy of the foot and impairment of its functioning increase the risk of various complications. Therefore, it is important to take early and appropriate multidisciplinary care of a foot with 'special needs'. In the above example, the immediate use of negative pressure treatment protected the structure of the foot from infection in Charcot arthropathy, as well as allowed for an effective healing of the wound.

\section{CONCLUSIONS}

As shown in the example above, the use of efficient methods of negative pressure therapy can be a recommended

[2] J.-M. Charcot, "Sur quelques arthropathies qui paraissent dependre d'une lesion du cerveau ou de la moelle epiniere," Arch Physiol Normale Pathol., vol. 1, pp. 161-178, 1868. compromise between radical surgical treatment and conservative, expectant management. In many cases, negative pressure therapy inhibits further foot damage. Negative pressure therapy does not, in any way, supersede other available therapeutic possibilities but it remains the only effective method of treatment for many patients.

\section{REFERENCES}

[1] H. X. Gao, E. E. Regier, and K. L. Close, "International diabetes federation world diabetes congress 2015." 2016.

[3] E. Gouveri and N. Papanas, "Charcot osteoarthropathy in diabetes: a brief review with an emphasis on clinical practice," World journal of diabetes, vol. 2, no. 5, p. 59, 2011.

[4] S. Malhotra, E. Bello, and S. Kominsky, "Diabetic foot ulcerations: biomechanics, charcot foot, and total contact cast," vol. 25, no. 2, pp. 66-69, 2012.

[5] N. L. Petrova, C. Moniz, D. A. Elias, M. Buxton-Thomas, M. Bates, and M. E. Edmonds, "Is there a systemic inflammatory response in the acute charcot foot?" Diabetes Care, vol. 30, no. 4, pp. 997-998, 2007.

[6] S. N. Eichenholz, "Charcot joints," Springfield, IL, USA.

[7] K. A. Chisholm and J. M. Gilchrist, "The charcot joint: a modern neurologic perspective," Journal of clinical neuromuscular disease, vol. 13 , no. 1 , pp. 1-13, 2011.

[8] A. I. Vinik and D. Ziegler, "Diabetic cardiovascular autonomic neuropathy," Circulation, vol. 115, no. 3, pp. 387-397, 2007.

[9] S. Gilbey, H. Walters, M. Edmonds, A. Archer, P. Watkins, V. Parsons, and A. Grenfell, "Vascular calcification, autonomic neuropathy, and peripheral blood flow in patients with diabetic nephropathy," Diabetic medicine, vol. 6 , no. 1 , pp. 37-42, 1989.

[10] P. Watkins, "Foot blood flow in diabetic neuropathy," 1983.

[11] P. Watkins and M. Edmonds, "Sympathetic nerve failure in diabetes," Diabetologia, vol. 25, no. 2, pp. 73-77, 1983.

[12] T. S. Purewal, D. E. Goss, P. J. Watkins, and M. E. Edmonds, "Lower limb venous pressure in diabetic neuropathy," Diabetes care, vol. 18, no. 3, pp. 377-381, 1995.

[13] M. J. Young, A. Marshall, J. E. Adams, P. L. Selby, and A. J. Boulton, "Osteopenia, neurological dysfunction, and the development of charcot neuroarthropathy," Diabetes Care, vol. 18, no. 1, pp. 34-38, 1995.

[14] N. Petrova, A. Foster, and M. Edmonds, "Calcaneal bone mineral density in patients with charcot neuropathic osteoarthropathy: differences between type 1 and type 2 diabetes," Diabetic medicine, vol. 22, no. 6, pp. 756-761, 2005.

[15] W. P. Grant, R. Sullivan, D. E. Sonenshine, M. Adam, J. H. Slusser, K. A. Carson, and A. I. Vinik, "Electron microscopic investigation of the effects of diabetes mellitus on the achilles tendon," The Journal of foot and ankle surgery, vol. 36, no. 4, pp. 272-278, 1997.

[16] S. Rajbhandari, R. Jenkins, C. Davies, and S. Tesfaye, "Charcot neuroarthropathy in diabetes mellitus," Diabetologia, vol. 45, no. 8, pp. 1085-1096, 2002.

[17] L. Sanders, "Diabetic neuropathic osteoarthropathy: the charcot foot," The high risk foot in diabettes mellitus, 1991.

[18] M. Assal and R. Stern, "Realignment and extended fusion with use of a medial column screw for midfoot deformities secondary to diabetic neuropathy," JBJS, vol. 91, no. 4, pp. 812-820, 2009.

[19] R. S. Dechent, C. R. Alcárcel, V. P. Romaguera, A. M. Caamaño, and F. A. Arana, "Role of the general surgeon in the early diagnosis and treatment of charcot'foot," Cirugía Española (English Edition), vol. 93 , no. 5, pp. 320-325, 2015 